УДК 811.111: 81'42

DOI https://doi.org/10.26661/2414-1135-2021-83-34

\title{
ТЕОРЕТИКО-МЕТОДОЛОГІЧНІ ЗАСАДИ ДОСЛІДЖЕННЯ ІННОВАЦЙНОЇ ОСВІТНЬОЇ КОМУНІКАЦІЇ В ЦИФРОВОМУ СЕРЕДОВИЩІ (НА МАТЕРІАЛІ ГЛОБАЛІЗОВАНИХ ЕВРОПЕЙСЬКИХ ТА СХІДНИХ МОВ)
}

\author{
Семеніст I. B. \\ кандидат історичних наук, \\ завідувач кафедри східних мов та перекладу \\ Київський університет імені Бориса Грінченка \\ вул. Бульварно-Кудрявська, 18/2, Київ, Україна \\ orcid.org/0000-0002-0847-8856 \\ i.semenist@kubg.edu.ua \\ Махачашвілі Р. К. \\ доктор філологічних наук, дочент, \\ завідувач кафедри романської філології та порівняльно-типологічного мовознавства \\ Київький університет імені Бориса Грінченка \\ вул. Бульварно-Кудрявська, 18/2, Київ, Україна \\ orcid.org/0000-0002-4806-6434 \\ r.makhachashvili@kubg.edu.ua
}

\begin{abstract}
Ключові слова: інноваційна освітня комунікація, IKT, тезаурус ичифрової освіти, гібридного навчання та цчифрових компетентностей, моделювання, феноменологічна неолінгвістика.
\end{abstract}

Основна увага в роботі зосереджена на дослідженні теоретико-методологічних принципів вивчення інноваційної освітньої комунікації в цифровому середовищі (інноваційна освітня комунікація в цифровому просторі у розумінні трансформаційних інноваційних шарів та комунікативного застосування, опосередкованого сучасними європейськими та східними мовами глобального спілкування - англійська, іспанська, французька, китайська, японська, відповідно). Проблема теоретичного та методологічного обгрунтування наскрізних принципів, напрямів, механізмів та результатів якісного моделювання макро- та мікроструктур вербальних засобів та засобів процесування у сфері цифрового освітнього спілкування, як консолідованого мовного та технологічного об'єкта, досліджується грунтовно. Мозаїчний, імітаційний, багатовимірний та рамковий підходи до розуміння складних динамічних лінгвістичних явищ та сутностей, пріоритетні для цього методологічного контексту, дозволили нам виявити онтологічну природу навчальних комунікаційних одиниць глобалізованих мов у сфері інноваційного освітнього спілкування. Тезаурус IКТ, електронного навчання, гібридного навчання, цифрових компетенцій, що сприяє інноваційному освітньому спілкуванню, побудований для визначення та категоризації ключових компонентів інноваційної кібертермінології, які своєю чергою сприяють побудові та функціонуванню середовища електронного навчання. Запропоновано моделювання макро-, мікро- та надструктур інноваційної освітньої комунікації та їх цифрову обробку на основі трьох основних принципів: 1) Інтернет-освітня антропосфера (антропне середовище у Всесвітній павутині); 2) зовнішньо-мережева антропосфера освіти (компоненти електронної реальності, функціонують поза сферою Всесвітньої павутини); 3) техногенна освітня антропосфера (переорієнтовані компоненти антропогенного середовища із заміщеним онтологічним параметром на однорідний антропний). Динамічна взаємодія структурних рівнів змістовного рівня IКТ у шарах інноваційної освітньої комунікації характеризується антропогенними та когнітивними параметрами змістовної площини, опосередкованими суб'єктивним та колективним когнітивним досвідом стейкхолдерів цифрової освіти, втіленого в рамках цифрової трансформації інноваційних комунікативних освітніх сценаріїв. 


\title{
THEORETICAL AND METHODOLOGICAL PRINCIPLES OF STUDY OF THE INNOVATIVE EDUCATIONAL COMMUNICATION IN THE DIGITAL REALM (BASED ON GLOBALIZED EUROPEAN AND ASIAN LANGUAGES)
}

\author{
Semenist I. V. \\ Doctor of Philosophy, \\ Head of the Department of Oriental Languages and Translation \\ Borys Grinchenko University of Kyiv \\ Bulvarno-Kudryavska-str., 18/2, Kyiv, Ukraine \\ orcid.org/0000-0002-0847-8856 \\ i.semenist@kubg.edu.ua \\ Makhachashvili R. K. \\ Doctor Habilitated of Philology, Associate Professor, \\ Head of the Department of Typology and Romance Languages \\ Borys Grinchenko University of Kyiv \\ Bulvarno-Kudryavska-str., 18/2, Kyiv, Ukraine \\ orcid.org/0000-0002-4806-6434 \\ r.makhachashvili@kubg.edu.ua
}

Key words: innovative educational communication, ICT, e-learning, hybrid learning, digital competences thesaurus, modelling, phenomenological neoliguistics..
The paper main focus is the inquiry into the theoretical and methodological principles of the study of the innovative educational communication in the digital realm (innovative educational communication in the digital ambient as construed by the transformative innovative strata and communicative application, facilitated by the modern European and Oriental languages of global communication - English, Spanish, French, Chinese, Japanese, accordingly). The problem of theoretical and methodological substantiation of cross-cutting principles, directions, mechanisms, and results of qualitative modeling of macro- and microstructures of verbal means and processing tools in the realm of digital educational communication, as a consolidated linguistic object, is investigated in depth. Mosaic, simulation, multidimensional, and framework approaches to understanding complex dynamic linguistic phenomena and entities, prioritized by this methodological context, allowed us to identify the ontological nature of educational communication units of the globalized languages in the sphere of innovative educational communication. The ICT, e-learning, hybrid learning, digital competencies thesaurus, that facilitates innovative educational communication, is structured to define and categorize the key components of innovative cyberterminology, instrumental to e-learning environment construction and functioning. Suggested are the innovative educational communication macro-, micro- and supra-structures modeling and digital processing based on three groundwork principles: 1) Intranet educational anthroposphere (the anthropic environment within World Wide Web); 2) Outernet educational anthroposphere (e-reality components, functions outside the realm of World Wide Web); 3) Technogenic educational anthroposphere (transoriented anthropic environment components with an anthropic-for-congenerous substituted ontological parameter). The dynamic interaction of the structural tiers of the ICTs content plane within the strata of innovative educational communication is characterized by the anthropogenic and cognitive parameters of the content plane, mediated by the subjective and collective cognitive experience of digital education stakeholders, embodied in the framework digital transformation of innovative communicative educational scenarios. 
Постановка проблеми. На новітньому етапі розвитку людства мова (як суспільний феномен) здебільшого являє собою індикатор тих технологічних змін, що відбуваються в суспільстві. Особливим чином це стосується сучасної англійської, яка на зламі тисячоліть набула функції своєрідної «метамови» цифрового середовища для різних культур $[2 ; 5 ; 15 ; 18]$. Це, безперечно, сприяє процесам «глобалізації» та всесвітньої інтеграції $[1 ; 3 ; 9 ; 17 ; 35 ; 37]$, що своєю чергою призводить до зміцнення позиції англійської мови як мови інтернаціональної комунікації [32; 33] та становить основи процесів гібридизації європейських та східних мов глобального спілкування у цифровому середовищі.

Саме тому в останні роки значною мірою зросли темпи збагачення словникового складу англійської мови та, як наслідок, інших мов міжнаціонального спілкування у цифровому просторі (іспанська, французька, німецька, китайська тощо). Як ніколи актуального змісту набуло поняття «неологізму» як рушійна сила прогресу мови $[13 ; 32$, с. 5]. Слід зазначити також, що особливо бурхливого розвитку в умовах всесвітніх карантинних обмежень 2020-2021 років набуває та сфера лінгво-комунікативних новоутворень мов глобального міжнародного спілкування, яка безпосередньо співвідноситься з науково-технічним прогресом та застосуванням цифрових технологій у сфері освіти [14].

Проблема теоретико-методологічного обгрунтування наскрізних принципів, напрямів, механізмів та результатів якісної динаміки макро- й мікроструктур словникового складу в царині комп'ютерного буття як консолідованого лінгвального об' єкта ще чекає на всебічне вивчення. Аналіз цього питання потребує залучення феноменологічного ракурсу $[20 ; 23 ; 29 ; 34 ; 52]$ дослідження комплексних мовних об'єктів 3 огляду на магістральне завдання феноменологічної епістемології - пізнання повної системи фактів свідомості (термін Мераба Мамардашвілі - [39; 40]), що конституюють дійсність. У межах окресленого методологічного виміру «феноменологічність» мовноі одиничі визначається як іiі кодифікативна спроможність до фіксачії результатів пізнавального досвіду та вияву в ній субстантних характеристик пізнаваних об'єктів та явищ. Запропонована у нашому доробку [13-15] лінгвістична адаптація феноменологічного підходу до теоретико-методологічного осмислення динаміки словникового складу сучасних мов глобального спілкування в комп'ютерному бутті спирається на поняття глобальної погосфери, синтетично усвідомленої як 1) множинність мовних одиниць, які $є$ умовно вичерпними феноменологічними реалізаціями абстрактних та емпіричних елементів різних сфер буття $[25 ; 38]$; 2) зона інтеграції мисленнєво-мовленнєвих континуумів (лінгво)культур [26].

Робоча гіпотеза дослідження полягає у тому, що: 1) феноменологічна природа інноваційної освітньої комунікації в цифровому середовищі

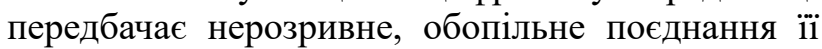
лінгвального та субстантного (онтологічного, епістемічного та антропологічного) аспектів у вертикальній площині взаємовиявлення діади явище :: сутність; 2) консолідовані субстантні характеристики макроструктури інноваційної освітньої комунікації в глобальному цифровому середовищі визначають феноменологічну специфіку конфігурації у статиці, наскрізної взаємодії та формально-змістових конституентів й інструментів іiі мікроструктури в динаміці.

Об'єктом дослідження виступає освітня комунікація в глобальному цифровому середовищі. Предмет аналізу - інноваційні мовно-технологічні моделі, засоби та механізми освітньої комунікації в цифровому середовищі. Метою статті $\epsilon$ визначення теоретико-методологічного підгрунтя моделювання засобів та мовно-технологічних механізмів інноваційної освітньої комунікації в глобальному цифровому середовищі.

Виклад основних матеріалів та результатів. Методологічно дослідження базується на таких вихідних положеннях:

- інноваційна одиниця мови (неологізм) та комунікації (оказіоналізм, неолемма) 3 погляду сучасних теорій номінації [45; 48; 49], неології [32; 33], термінології [31] та словотвору $[33 ; 51]$ позиціонується як амбівалентний мовний знак, властивості якого задовольняють діалектичній єдності у протиставленні діад фіксованість :: відкритість, консолідованість :: дисипативність, статика :: динаміка форми та змісту як онтологічного витоку механізмів високодинамічного розвитку систем сучасних мов глобальної комунікації в цифровому просторі;

- проблематика мовного кодування та картинування різнотипних сфер актуальної та цифрової соціальної дійсності визначається в лінгвоонтологічному $[19 ; 30 ; 42 ; 50]$, лінгвокогнітивному $[11 ; 12 ; 16 ; 24 ; 36 ; 43 ; 46 ; 47]$, лінгвокультурному $[10 ; 21 ; 22 ; 26]$, синергетичному [17; 18;33] ракурcax, у межах яких мова інтерпретується як інструмент накопичення, ієрархічного підпорядкування та трансляції знань про оточуючу дійсність соціально-культурне явище, конституенти якого беруть участь у конструюванні цілісних та фрагментарних образів дійсності різного ступеня абстракції; як відкрита нелінійна система, здатна до формально-змістової самоорганізації у процесі розвитку;

- вивчення складних динамічних мовних та комунікативних явищ зумовлене методологічним 
контекстом постмодерністської парадигми наукового мислення другої половини XX - початку XXI ст. загалом [2-4; 7; 28; 44] та лінгвістичної науки зокрема $[13 ; 25 ; 50 ; 48]$, визначається мозаїчністю та міждисциплінарним характером методологічних підходів до досліджуваних об'єктів.

До вивчення вибраного об'єкта - інноваційної освітньої комунікації в глобальному цифровому середовищі - як методологічна база залучаються принципи феноменологічної неолінгвістики [13], яка передбачає консолідацію лінгвального та субстантного аспектів досліджуваних інноваційних мовних, комунікативних та технологічних явищ, що підпорядковані нерозривній, взаємозворотній єдності понять феномен :: сутність.

Застосована в дослідженні адаптація феноменологічного підходу до теоретико-методологічного осмислення інноваційної освітньої комунікації в цифровому середовищі спирається на синтетичне усвідомлення низки понять: поняття про логосферу як 1) множинність мовних одиниць, які є умовно вичерпними феноменологічними реалізаціями абстрактних та емпіричних елементів різних сфер буття (М. Бахтін, Е. Пауераннен; Р. Махачашвілі; Д. Кранц), 2) зону інтеграції мисленнєво-мовленнєвих континуумів (лінгво) культур (Р. Барт, Г.Д. Гачев, А.Ф. Лосєв), семіосферу - множинність культурно-релевантних універсальних смислів та значень (Ю. Лотман), пневматосферу - множинність трансцендентних духовних смислів (П. Флоренський), ноосферу множинність інтегральних інтелектуальних смислів та комунікативних практик, породжених функціональним синтезом культури та технології (В. Вернадський).

У межах феноменологічного підходу (Е. Гуссерль, Р. Інгарден, М.К. Мамардашвілі, Г. Шпет) глобальна семіотична інтегрованість макро- i мікроструктур інноваційної освітньої комунікації в глобальному цифровому середовищі ідентифікується як забезпечена та реалізована за рахунок детермінаційної взаємодії різносубстратних (мовних, часопросторових, ессенціальних, антропологічних та соціальних) параметрів цієї інноваційної комунікативної логосфери, з огляду на значну синхронну щільність темпів та результатів паралельного розвитку вербального, онтологічного та антропологічного континуумів глобального цифрового середовища [2-4; 6-9; 24; 27; 35; 37]. Логоцентричний ракурс $[25 ; 38 ; 39]$ розгляду освітньої комунікації в глобальному цифровому середовищі визначає іiі феноменологічну природу через ідентифікацію знакового (структурно-змістового) субстрату як емпіричного джерела та результату прояву субстантних характеристик реальності.

У новому тисячолітті система інновацій природних мов та комунікації, яка співвідноситься зі сферою новітніх комп'ютерних технологій та динаміки комп'ютерного буття загалом набуває бурхливого та інтегрованого розвитку, що забезпечується низкою лінгвальних та екстралінгвальних передумов:

1) синхронізованість темпів оновлення різнорівневого складу природних мов глобального спілкування у відповідній галузі та темпів і обсягів виникнення та розгалуження субстантної, об'єктної, феноменологічної, антропологічної сфер цифрової дійсності [37], що виявляється у значних, порівняно з іншими буттєвими сферами в досліджуваний період, кількісних покажчиках обсягів поповнення інноваційного (узуального та потенціального) вербального інструментарію мов глобального спілкування в різних соціальних сферах: $\approx 20$ узуальних новотворів сфери цифрового буття на 1 міс., що становить середню кількість 180 узуальних новотворі на 1 рік ( $49-60 \%$ загальної вибірки узуальних новотворів сучасних мов глобального спілкування за даними конвенційних лексикографічних джерел та автоматизованих лексикографічних реєстрів WordSpy, WorldWideWords, The Merriam-Webster Online тощо);

2) ізоморфізм мовного кодування різносубстратних структур (онтологічної, гносеологічної, антропологічної) комп'ютерного та некомп'ютерного буття [13];

3) гнучкість та адаптивність розвитку багаторівневого складу глобалізованих мов спілкування у цифровому середовищі [15], що актуалізується шляхом інформоємності, семіотичної гібридизації лінгвальних новотворів мов глобального спілкування у цифровому середовищі, вияву потенції до трансформації їх ознак морфологічного статусу, морфологічної функції тощо.

Означений стан наочного та доступного для спостереження ситуативного паралелізму процесів виникнення та розвитку інноваційних ессенцүійних елементів (простір, час, субстанція), гносеологічних елементів (інформація, епістема тощо), антропологічних елементів (екзистенційний стан, тип ідентичності тощо) цифрового буття та їх лінгвальних й комунікативних корелятів (мовний знак, мовна форма, мовне значення, мовний зміст) визначає методологічну релевантність позиціонування означеного сегмента лінгво-комунікативної та соціальної (зокрема освітньої) дійсності як особливого типу логосфери, зокрема інноваційної логосфери, що становить собою синхронну периферію логосфери сучасної глобальної лінгвокультури у цифрову добу.

Вважаємо за доцільне виділити з конфігурації зазначеного макрофеномена окремий галузевий об'єкт розвідки - інноваційну освітню комунікацію в глобальному цифровому середовищі. 
Інноваційна освітня комунікація в глобальному цифровому середовищі розуміється як вертикально інтегрована на макро- та мікрорівні множинність узуальних мовних інновачій та інноваційних комунікативних практик, щуо за своєю типологічною специфікою є умовно вичерпними феноменологічними корелятами різносубстратних елементів та технологій цифрового буття.

Виокремлюємо характеристики інноваційної освітньої комунікації:

(1) спроможність до феноменологізаії субстантної своєрідності глобального цифрового середовища на рівні сигніфікативних характеристик вербальних одиниць, що конституюють відповідну профільну комунікативну сферу. Наведена характеристика логосфери інноваційної освітньої комунікації у цифровому середовищі виявляється на рівні зовнішньої форми пї дискретних одиниць. Напр., за рахунок комбінації конфігурацій зовнішньої та внутрішньої форми дискретних одиниць логосфери інноваційної освітньої комунікації: напр., e-learning 2.0 (е-learning N.0) - візуальні та технологічні конфігурації Інтернет-простору, що уможливлюють освітню взаємодію згідно відповідного етапу розвитку технологій, де 2.0/N.0 - метонімічна семіотична репрезентація змістового елемента «нова (удосконалена) версія» (операційної системи, програмного забезпечення, програмного продукту тощо);

(2) змістова та структурна щільність обсягу, рівномірність та умовна вичерпність інноваційної кодифікації загалу різносубстратних елементів цифрового середовища. Ця характеристика зумовлює принцип інтегрованості макроструктури інноваційної освітньої комунікації в глобальному цифровому середовищі, який визначається феноменологічною (екстенсіональною, сигніфікативною) корельованістю іï дискретних елементів із:

1) конструктивними елементами цифрового середовища загалом - простір, час, субстаниія, явище, сутність (напр.: феноменологічна кореляція елементу «субстанція» - Webrarian (телескопне зрощення $\mathrm{Web}+(\mathrm{lib}) \mathrm{rarian}-$ - суб 'єкт інноваціийної освітньої комунікації, фахівець з архівачіі цифррових баз даних);

2) конструктивними елементами знання/ пізнання - інформація, епістема, поняття, кониепт (напр.: феноменологічна кореляція елементу «інформація» - information demise - руйнування систем збереження даних; data spill - перенасичення комунікативного простору даними);

3) конструктивними елементами людської свідомості/самосвідомості ідентифікаиія, ідентичність, індивідуальність, соиіальність (напр., низка новотворів - маніфестацій елементу «суб' Єкт»/《самість» за рахунок різнотипних механізмів субстантивізації семантичної та референт- ної ознаки «я» - narb (телескопне зрощення від nar(rative)+(b)it - фрагмент особистої інформаиії про комуніканта, який можна відстежини у циифровому середовищі).

Основна увага в межах розвідки зосереджена на дослідженні моделей та інструментів всебічного структурування інноваційної освітньої комунікації в цифровому середовищі (інноваційна освітня комунікація в цифровому середовищі в розумінні трансформаційних інноваційних шарів та комунікативного застосування, опосередковані сучасними європейськими та східними мовами міжнародного спілкування - англійська, іспанська, французька, китайська, японська відповідно).

Мозаїчний, імітаційний, багатовимірний та рамковий підходи до розуміння складних динамічних лінгвістичних явищ та сутностей, пріоритетні для цього методологічного контексту, дозволили нам виявити онтологічну природу комунікаційних одиниць глобалізованих мов у сфері інноваційного освітнього спілкування.

Висновки. Тезаурус інформаційно-комунікативних технологій, електронного навчання, гібридного навчання, цифрових компетенцій як лінгвокогнітивна пресупозиція інноваційної освітньої комунікації побудований для визначення та категоризації ключових компонентів інноваційної кібертермінології, що сприяють побудові та функціонуванню середовища електронного навчання. Запропоновано моделювання макро-, мікро- та супра-структур інноваційної освітньої комунікації та їх цифрову обробку в координатах трьох основних вимірів: 1) Інтернет-освітня антропосфера (антропне середовище у Всесвітній павутині); 2) зовнішньомережева антропосфера освіти (компоненти електронної реальності, функціонують поза сферою Всесвітньої павутини); 3) техногенна освітня антропосфера (переорієнтовані компоненти антропогенного середовища із заміщеним онтологічним параметром на однорідний антропний).

Динамічна взаємодія структурних рівнів змістовного рівня IКТ у шарах інноваційної освітньої комунікації характеризується антропогенними та когнітивними параметрами змістовної площини, опосередкованими суб'єктивним та колективним когнітивним досвідом стейкхолдерів цифрової освіти, втіленим у рамках цифрової трансформація інноваційних комунікативних освітніх сценаріїв. Тезаурус IКТ, електронного навчання, гібридного навчання, цифрових компетенцій виявляє феноменологічну (номінативну, референційну, денотативну, сигніфікативну) здатність до конвергованого кодування на рівні системи елементів своєї внутрішньої та зовнішньої форми всіх зазначених вище параметрів. 
Специфіка Тезаурусу IKT, електронного навчання, гібридного навчання, цифрових компетенцій визначається ізоморфним характером інтегрованості структури його зовнішньої та внутрішньої форми та інтегрованості макроструктури інноваційної освітньої комунікації в глобальному цифровому середовищі.

Перспективи. Перспективи дослідження полягають у розширенні дослідження щодо оцінки параметрів розвитку цифрової грамотності як складника інноваційної освітньої комунікації для окремих груп мов, для різних типів засобів електронного навчання, що використовуються для засвоєння та застосування мов глобальної комунікації, а також діагностики міждисциплінарних тенденцій оцифрування освітніх комунікативних форматів у країнах Азії, Північної та Південної Америки та Європи.

\section{ЛІТЕРАТУРА}

1. Bell D. Social Framework of the Information Society. Oxford : Oxford U. Press, 1987. 315 p.

2. Davis E. Techgnosis: Myth, Magic and Mysticism in the Age of Information. NY : New York Publishers, Inc., 2001. 377 p.

3. Dobson H., Kürschne B. An Introduction to Responsible Technology. URL: https://tech2impact.com/an-introduction-to-responsible-technology/.

4. Gelernter D. Virtual Realism. Oxford : Oxford University Press, 1998. 138 p.

5. Hausser R. Foundations of Computational Linguistics. Springer : Verlag Berlin Heidelberg, 1999. $534 \mathrm{p}$.

6. Heeter C. Implications of new interactive technologies for conceptualizing communication. Media use in the information age. Hillsdale, $\mathrm{NJ}$ : Erlbaum, 1989, pp. 85-108.

7. Heim M. Virtual Reality: Practice and Promice. LA : Wesport Publishers, 1994. 233 p.

8. James L. Exploring what "responsible technology" means. URL: https://medium.com/doteveryone/exploring-what-responsible-technology-means-4f2a69b50a61.

9. Johnson F. Shall I Compare Thee to a Swarm of Insects? Searching for the Essence of the World Wide Web. The New York Times. 2003. Pp. 10-12.

10. Knight S. Making authentic cultural and linguistic connections. Hispania. 1994, Vol. 77, pp. 289-294.

11. Lakoff G. Women, fire and dangerous things. Chicago : CUP, 1987. 614 p.

12. Langacker R. W. Cognitive Grammar. The Oxford Handbook of Cognitive Linguistics. Oxford : Oxford Univ. Press, 2007, pp. 421-462.

13. Makhachashvili R., Models and Digital Diagnostics Tools for the Innovative Polylingual
Logosphere of Computer Being Dynamics. Italian-Ukrainian Contrastive Studies: Linguistics, Literature, Translation. Peter Lang GmbH Internationaler Verlag der Wissenschaften, Berlin, 2020. pp. 99-124.

14. Makhachashvili, Rusudan and Semenist, Ivan. Phenomenological principles of global innovative logosphere of computer being construction (based on European and oriental languages). Вчені записки ТНУ імені В. І. Вернадського. 2021. № 32(71) (1). Pp. 195-202.

15. Makhachashvili R., Semenist I. ICT Thesaurus Modelling Recommendations (based on innovations of European and Oriental languages). Studia Filologiczne, 7, 2020, pp. 117-128.

16. Minsky, M. A Framework for Representing Knowledge. In Frame Conceptions and Text Understanding, 1979, pp. 1-25.

17. Monnin A. Humanity and Digital Characters in Virtual Worlds: Crossing the Fictional Boundaries. Posthumanity : Merger and Embodiment. Oxford, UK : Inter-Disciplinary Press, 2010, pp. 126-131.

18. Nyce J. M. From Memex to Hypertext. NY: Kahn Publications, 1994. 472 p.

19. Searle J. Minds, Brains, and Science. Oxford : Oxford U. Press, 1984. 142 p.

20. Zahavi D. Husserl's Phenomenology. Palo Alto : Stanford University Press, 2003. 312 p.

21. Андреева И.В. Ценностная картина мира как лингвистическая и философская категорія. Аналитика культурологии. 2006. № 3. C. 14-21.

22. Андрейчук H.I. Семіотика лінгвокультурного простору Англії кінця XV - початку XVII століття. Львів : Видавництво Львівської політехніки, 2011. 277 с.

23. Бабушкин В.У. Феноменологическая философия науки - критический анализ. Москва : Наука, 1985. 246 с.

24. Баксанский O.Е., Кучер Е.Н. Когнитивное репрезентирование как механизм виртуализации реальности. Вируалистика: экзистенциальные и эпистемологические аспектыл. Москва : Прогресс-Традиция, 2004. C. 262-285.

25. Барт Р. Избранные работы: Семиотика: Поэтика. Москва : Прогресс, 1989. 616 с.

26. Бахтин М.М. Эстетика словесного творчества. Москва : Искусство, 1979. 424 с.

27. Борчиков С.А. Метафизика виртуальности. Труды лаборатории виртуалистики. 2000. Вып. 8. С. 29-33.

28. Будко В.В. Адекватность научного познания. Харьков : Логос, 1990. 154 с.

29. Гуссерль Э. Картезианские размышления. Санкт-Петербург : Наука, 2001. 516 с. 
30. Девтерев И.В. Философский анализ феномена интерактивной научной деятельности в INTERNET (феноменологический, эвристический и прагматический аспекты). Киев, 2000. $188 \mathrm{c}$.

31. Дудок P.I. Проблема значення та смислу терміна в гуманітарних науках. Львів : Видавничий центр ЛНУ імені Івана Франка, 2009. 358 c.

32. Зацний Ю.А. Інновації у словниковому складі англійської мови початку XXI століття : англо-український словник. Вінниця : Нова Книга, 2008. 360 с.

33. Снікєєва С.М. Система словотвору сучасної англійської мови: синергетичний аспект (на матеріалі новоутворень кінця XX - початку ХХІ століть). Київ, 2011. 438 с.

34. Ингарден Р. Введение в феноменологию Эдмунда Гуссерля. Москва : Дом интеллектуальной книги, 1999. 267 с.

35. Камша В.П., Камша Л.С., Камша Ю.В. Про кібернетику другого етапу НТР. Складні системи і процеси. 2010. № 1 (17). С. 25-41.

36. Карасик В.И. Языковой круг: личность, концепты, дискурс. Волгоград : Перемена, 2002. $477 \mathrm{c}$.

37. Кутырев В.А. Культура и технология: борьба миров. Москва : Прогресс-Традиция, 2001. 336 с.

38. Лосев А.Ф. Вещь и имя. Бытие. Имя. Космос. Москва : Мысль, 1993. С. 805-872.

39. Мамардашвили М.К., Пятигорский А.М. Символ и сознание. Метафизические рассуждения о сознании, символике и языке. Москва : Школа, 1997. 216 с.

40. Мамардашвили М.К. Как я понимаю философию. Избр. ст., докл., выступ., интервью. Москва : Прогресс, 1999. 415 с.

41. Мартинюк А.П. Конструювання гендеру в англомовному дискурсі. Харків : Константа, 2004. $292 \mathrm{c}$.

42. Мартинюк С.С. Метафізичні виміри людського буття. Запоріжжя : Запорізький державний університет, 2001. 198 с.

43. Маслова В.А. Введение в когнитивную лингвистику. Москва : Флинта, 2007. 296 с.

44. Мерло-Понти М. Феноменологія сприйняття. Київ : Український Центр духовної культури, 2001. $552 \mathrm{c}$.

45. Морозова А.К. Проблема значения в свете современных семантических теорий. Вісник ХНУ. 2004. № 635. С. 114-117.

46. Попова 3.Д., Стернин И.А. Когнитивная лигвистика. Москва : АСТ, Восток-Запад, 2007. $315 \mathrm{c}$.

47. Потапенко C.I. Орієнтаційна семантика: дискурсивне втілення. Вісник Львівського універcuтету. 2011. Вип. 52. С. 253-261.
48. Селиванова Е.А. Процессы неологизации в ракурсе динамики этносознания. Лексико-грамматические инновачии в современных восточнославянских языках. Днепропетровск : Пороги, 2007. С. 57-60.

49. Степанов Ю.С. В трёхмерном пространстве языка: Семиотические проблемы лингвистики, философии, искусства. Москва : Наука, 1986. $336 \mathrm{c}$.

50. Хайдеггер М. Язык. Москва : Фолио, 2003. $374 \mathrm{c}$.

51. Шепель Ю.А. Міжгалузева термінологічна омонімія у сучасній англійській мові. Дніпродзержинськ : ДДТУ, 2010. 335 с.

52. Шпет Г. Явление и смысл (Феноменология как основная наука и ее проблемы). Москва : Наука, 2001. 219 с.

\section{REFERENCES}

1. Andreeva I.V. (2006) Tsennostnaya kartina mira kak lingvisticheskaya i filosofskaya kategoriya. [Axiologial worldview as linguisitic an philosophical category]. Culture Analitics, V. 3, pp. 14-21 [In Russian].

2. Andreychuk N.I. (2011) Semiotika lingvokulturnogo prostoru Angliyi kintsia XV pochatku XVII stolittya. [Semiotics of linguocultural space of England in the late XVth early XVII centuries]. Lviv : Lviv Polytechnic Press, 277 p. [In Ukrainian].

3. Babushkin V.U. (1985) Fenomenologicheskaya filosofiya nauki - kriticheskiy analiz. [Phenomenological philosophy of science - critical review] M. : Academia, 246 p. [In Russian].

4. Bakhtin M. M. (1979) Estetika slovesnogo tvorchestva. [Aethetics of verbal art]. M. : Art, 424 p. [In Russian].

5. Baksanskiy O. E., Kucher E. N. (2004) Kognitivnoe reprezentirovanie kak mehanizm virtualizatsii realnosti. [Cognitive representation as a mechanism of virtual reality]. Virtualistics: existential and epistemological aspects. M. : Progress-Tradition, pp. 262-285 [In Russian].

6. Barthes R. (1989) Izbrannyie rabotyi: Semiotika: Poetika. [Selected readings on semiotics: Petics]. M. : Progress, 616 p. [In Russian].

7. Bell D. (1987) Social Framework of the Information Society. Oxford : Oxford U. Press, $315 \mathrm{p}$.

8. Borchikov S. A. (2000) Metafizika virtualnosti. [The metaphysics of virtuality]. Proceeding of virtualistics laboratory. Issue. 8. pp. 29-33 [In Russian].

9. Budko V. V. (1990) Adekvatnost nauchnogo poznaniya. [The adequacy of scientific inquiry]. Kharkiv : Logos, 154 p. [In Russian]. 
10. Davis E. (2001) Techgnosis: Myth, Magic and Mysticism in the Age of Information. NY : New York Publishers, Inc., 377 p.

11. Devterev I. V (2000) Filosofskiy analiz fenomena interaktivnoy nauchnoy deyatelnosti $\mathrm{v}$ INTERNET (fenomenologicheskiy, evristicheskiy i pragmaticheskiy aspektyi). [Philosophical analysis of the phenomenon of interactive scientific activity in the INTERNET (phenomenological, heuristic and pragmatic aspects)]. K., 188 p. [In Russian].

12. Dobson H., Kürschne B. (2021) An Introduction to Responsible Technology. Retrieved from: https://tech2impact.com/an-introduction-toresponsible-technology/.

13. Dudok R. (2009) Problema znacheniya ta smyslu termina $\mathrm{v}$ gumanitarnykh naukakh [Problem of the term meaning and content in Liberal Arts]. Lviv : Lviv National University Press. 358 p. [In Ukrainian].

14. Gelernter D. (1998) Virtual Realism. Oxford : Oxford University Press, $138 \mathrm{p}$.

15. Hausser R. (1999) Foundations of Computational Linguistics. Springer : Verlag Berlin Heidelberg, $534 \mathrm{p}$.

16. Heeter C. (1989) Implications of new interactive technologies for conceptualizing communication. Media use in the information age. Hillsdale, NJ : Erlbaum, pp. 85-108.

17. Heidegger M. (2003) Yazyk. [Language]. M. : Folio, 374 p. [In Russian].

18. Heim M. (1994) Virtual Reality: Practice and Promice. LA : Wesport Publishers, $233 \mathrm{p}$.

19. Husserl E. (2001) Kartezianskie razmyishleniya. [Cartesian musings] SPb. : Academia, 516 p. [In Russian].

20. Ienikieieva S. M. (2011) Systema slovotvoru suchasnoi anhliiskoi movy: synerhetychnyi aspekt (na materiali novoutvoren kintsia XX pochatku XXI stolit). [Word-building system of the modern English: based on the innovations of the late XX - early XXI century]. K., $438 \mathrm{p}$. [In Ukrainian].

21. Ingarden R. (1999) Vvedenie v fenomenologiyu Edmunda Gusserlya. [Introduction to Edmund Husserl's phenomenology]. M. : Intellectual book house, 267 p. [In Russian].

22. James L. (2020) Exploring what "responsible technology" means. URL: https://medium.com/ doteveryone/exploring-what-responsible-techno logy-means-4f2a69b50a61.

23. Johnson F. (2003) Shall I Compare Thee to a Swarm of Insects? Searching for the Essence of the World Wide Web. The New York Times. Pp. 10-12.

24. Kamsha V.P., Kamsha L.S., Kamsha Yu.V. (2010) Pro kibernetyku druhoho etapu NTR.
[On cybernetics of the $2^{\text {nd }}$ stage of STR]. Complex systems and processes, V. 1 (17). Pp. 25-41 [In Russian].

25. Karasik V.I. (2002) Yazyikovoy krug: lichnost, kontseptyi, diskurs. [Language circle: personality, context, discourse]. Volgograd : Peremena, $477 \mathrm{p}$. [In Russian].

26. Knight S. (1994) Making authentic cultural and linguistic connections. Hispania, Vol. 77, pp. 289-294.

27. Kutyirev V.A. (2001) Kultura i tehnologiya: borba mirov. [Culture and technology: the clash of the worlds] M., Progress-Tradition, 336 p. [In Russian].

28. Lakoff G. (1987) Women, fire and dangerous things. Chicago : CUP, $614 \mathrm{p}$

29. Langacker R. W. (2007) Cognitive Grammar. The Oxford Handbook of Cognitive Linguistics. Oxford : Oxford Univ. Press, pp. 421-462.

30. Losev A.F. (1993) Vesch i imya. [The thing and the name]. Existence. Name. Cosmos. M. : Myisl, p. 805-872 [In Russian].

31. Zatsnyi Yu.A. (2008) Innovatsii u slovnykovomu skladi anhliiskoi movy pochatku XXI stolittia: anhlo-ukrainskyi slovnyk [Innovations in vocabulary of the English language at the beginning of the XXIst century]. Vinnytsia : Nova Knyha [in Ukrainian].

32. Makhachashvili, Rusudan and Semenist, Ivan (2021) Phenomenological principles of global innovative logosphere of computer being construction (based on European and oriental languages). Vcheni zapyski TNU V. Vernadskogo [V. Vernadsky Tavria National University Academic Bulletin], № 32(71) (1). Pp. 195-202.

33. Makhachashvili R. (2020) Models and Digital Diagnostics Tools for the Innovative Polylingual Logosphere of Computer Being Dynamics. Italian-Ukrainian Contrastive Studies: Linguistics, Literature, Translation. Monograph. Peter Lang $\mathrm{GmbH}$ Internationaler Verlag der Wissenschaften, Berlin, pp. 99-124.

34. Makhachashvili R., Semenist I. (2020) ICT Thesaurus Modelling Recommendations (based on innovations of European and Oriental languages). Studia Filologiczne, V. 7, pp. 117-128.

35. Mamardashvili M. K. (1999) Kak ya ponimayu filosofiyu. [How I understand philosophy]. Selected papers, documents and talks. M. : Progress, 415 p. [In Russian].

36. Mamardashvili M.K., Pyatigorskiy A.M. (1997) Simvol i soznanie. [Symbol and consciousness]. Metaphysical musings on consciousness, symbolism and language. M. : Shkola, 216 p. [In Russian].

37. Martinyuk A. P. (2004) Konstruyuvannya genderu v anglomovnomu diskursi. [Construction 
of gender in the English discourse]. Kharkiv : Constanta, 292 p. [In Ukrainian].

38. Martyniuk S. S. (2001) Metafizychni vymiry liudskoho buttia. [Metaphysical dimentionas of the human existence]. Zaporizhzhia : ZSU Press, 198 p. [In Ukrainian].

39. Maslova V.A. (2007) Vvedenie v kognitivnuyu lingvistiku. [Introduction to cognitive linguistics]. M. : Flinta, 296 p. [In Russian].

40. Merlo-Ponty M. (2001) Fenomenolohiia spryiniattia. [Phenomenology of preception]. Kyiv : Ukrainian ceter for spiritual culture, $552 \mathrm{p}$. [In Ukrainian].

41. Minsky M.A. (1979) Framework for Representing Knowledge. In Frame Conceptions and Text Understanding, pp. 1-25.

42. Monnin A. (2010) Humanity and Digital Characters in Virtual Worlds: Crossing the Fictional Boundaries. Posthumanity : Merger and Embodiment. Oxford, UK : Inter-Disciplinary Press, pp. 126-131.

43. Morozova A.K. (2004) Problema znachenyia v svete sovremennykh semantycheskykh teoryi. [The issue of meaning in veiew of modern semantic theories]. KhNU Boulletin. V. 635, pp. 114-117 [In Russian].

44. Nyce J.M. (1994) From Memex to Hypertext. NY: Kahn Publications, $472 \mathrm{p}$.

45. Popova Z.D., Sternin I.A. (2007) Kognitivnaya ligvistika. [Cognitive linguistics]. M. : AST, East-West, 315 p. [In Russian].
46. Potapenko S. I. (2011) Oriientatsiina semantyka: dyskursyvne vtilennia. [Orientational semantics]. Lviv University Boulletin, V. 52, p. 253-261 [In Russian].

47. Searle J. (1984) Minds, Brains, and Science. Oxford : Oxford U. Press, $142 \mathrm{p}$.

48. Selivanova E.A. (2007) Processy neologizacii $\mathrm{v}$ rakurse dinamiki e'tnosoznaniya. Leksikogrammaticheskie innovacii $\mathrm{V}$ sovremenny' $\mathrm{x}$ vostochnoslavyanskix yazykax. [Neologization processes through the lens of ethnic consciousness dynamics]. Dnepropetrovsk: Porogi, pp. 57-60 [In Russian].

49. Shepel Yu.A. (2010) Mizhhaluzeva terminolohichna omonimiia u suchasnii anhliiskii movi. [Cross-sectorial terminological homonymi in the modern English]. Dniprodzerzhynsk : DDTU, 335 p. [In Ukrainian].

50. Shpet G. (2001) Yavlenie i smysl (Fenomenologiya kak osnovnaya nauka i ee problemy). [Phenomenon and Sense (Phenomenology as a core science and its issues]. M. : Academia, 219 p. [In Russian].

51. Stepanov Yu. S. (1986) V tryoxmernom prostranstve yazyka: Semioticheskie problemy lingvistiki, filosofii, iskusstva. [In the 3D space of the language: Semiotic issues of linguistics, philosophy and art]. M. : Academia, 336 p. [In Russian].

52. Zahavi D. (2003) Husserl's Phenomenology. Palo Alto : Stanford University Press, 2003. 312 p. 